\title{
Bioassay-guided isolation of allelochemicals from Avena sativa L.: allelopathic potential of flavone $C$-glycosides
}

\author{
Claudia de Bertoldi · Marinella De Leo • \\ Alessandra Braca · Laura Ercoli
}

Received: 8 October 2008/ Accepted: 22 June 2009 / Published online: 5 July 2009

(C) Birkhäuser Verlag, Basel/Switzerland 2009

\begin{abstract}
The allelopathic potential of oat (Avena sativa L., var. Argentina, Poaceae, Cyperales) was investigated under field and laboratory conditions. In field trials, oat plants provided an effective control of weeds, showing a species-specific impact: the most abundant weed species, Picris echioides was reduced by $94 \%$ in number of individuals. Aerial parts of oat plants, harvested immediately before soil incorporation, were utilized in a bioassay-guided isolation, which was aimed at identifying the phytotoxic compounds in a methanol/water extract of the aerial parts of the plants. Further partitions of extract gave an active $n$-butanol portion composed of flavonoids and saponins. Phytotoxic activity was detected for the flavonoid fraction, whereas no activity was found for the saponin mixture. Germination of an indicator species, lettuce (Lactuca sativa L.), was completely inhibited at flavonoid concentrations of $6.7,10.0$, and $20.0 \mathrm{mg} / \mathrm{mL}$, and conversely the number of abnormal seedlings was greatly increased from $2 \%$ of control to over $96 \%$ at concentrations equal to 6.7 and $10.0 \mathrm{mg} / \mathrm{mL}$. Analysis of the flavonoid fraction by ESI-MS techniques identified two components of the mixture as isoorientin 2-O-glucoside and isovitexin $2^{\prime \prime}$ - $O$-arabinoside. Saponins were characterized as avenacoside A, avenacoside B, 26-desglucoavenacoside A, and
\end{abstract}

C. de Bertoldi and M. De Leo contributed equally to this work.

C. de Bertoldi $\cdot$ L. Ercoli $(\bowtie)$

Scuola Superiore Sant'Anna, Piazza Martiri della Libertà 33, 56127 Pisa, Italy

e-mail: ercoli@sssup.it

M. De Leo · A. Braca

Dipartimento di Scienze Farmaceutiche,

Università di Pisa, Via Bonnano 33, 56126 Pisa, Italy 26-desglucoavenacoside B. Both flavone $C$-glycosides and saponins were isolated previously from oat.

Keywords Avena sativa (Poaceae, Cyperales) . Allelochemicals - Flavone $C$-glycosides .

Mass spectrometry

\section{Introduction}

Allelopathy is referred to as any direct or indirect harmful or beneficial effects of one plant (including microbes) on other plants in its vicinity through chemicals released into the environment (Rice 1984). Allelopathy is as an important mechanism of plant interference determined by the release into the rhizosphere of plant secondary metabolites (Inderjit 2001, 2005).

Allelopathy plays a significant role in both natural and agricultural ecosystems. In natural environments, allelopathy has been implicated in plant invasions, which is a major ecological problem (Bousquet-Mélou et al. 2005). In agriculture, the release of toxic substances into the soil can be exploited not only for sustainable cropping systems in crop rotation, but also for weed management systems through the use of cover crops (Putnam 1986; Weston 1996; Duke et al. 2000a; Weston and Duke 2003; Inderjit et al. 2005).

Chemicals with allelopathic potential have been detected in a large number of plant parts and organs, including leaves, stems, roots, flowers, seeds, and buds, which are released into the soil rhizosphere by a variety of mechanisms, such as decomposition of residues, volatilization, and root exudation (Weston 1996). The diversity of secondary metabolites produced by plants is vast, and chemical structures range from simple hydrocarbons to 
complex polycyclic aromatics. Nearly every class of secondary products or metabolites has been implicated in allelopathic interference (Weston and Duke 2003). Novel secondary metabolites with biological activity of potential utility as pharmaceuticals and pest-management products have been isolated and identified from higher plants (Duke et al. 2002). However, following Duke et al. (2000a), considering the large number of plant-derived compounds identified, only a few potential uses have been discovered.

Chemicals with allelopathic effects have been found in oat roots and shoots. These include scopoletin and its glucoside in the former and L-tryptophan in the latter (Fay and Duke 1977; Kato-Noguchi et al. 1994). More recently, Bahraminejad et al. (2008) reported an antimicrobial activity of flavonoids and saponins isolated from oat shoots. Moreover, flavone $C$-glycosides in oat have been identified as a novel defense against plant-parasitic nematodes (Soriano et al. 2004).

The search for allelochemicals in plants may be approached using different methods. These include bioassay-guided isolation, fractionation-driven bioassay, isolate and assay, and biochemical combinatorial chemistry approaches (Duke et al. 2000a). Duke et al. (2000a, b), Rimando et al. (2001), and Duke et al. (2002) suggest bioassay-guided isolation to be the best approach to discover natural phytotoxins and novel sites of action when the active component is not known.

In order to determine the allelopathic potential of oat (Avena sativa L., var. Argentina, Poaceae, Cyperales), field and laboratory experiments were carried out. A weed suppressive ability was determined in field conditions, following soil incorporation of the crop. Above-ground plant biomass, harvested immediately before soil incorporation, was utilized in a bioassay-guided isolation, in which we aimed to identify phytotoxic compounds.

\section{Materials and methods}

\section{Field experiment}

Oat was grown in open fields at the Experimental Research Station of the Department of Agronomy and Agroecosystem Management, University of Pisa, at S. Piero a Grado, near Pisa, Italy $\left(43^{\circ} 67^{\prime} \mathrm{N}, 10^{\circ} 30^{\prime} \mathrm{E}, 5 \mathrm{~m}\right.$ above sea level) from October 2006 to March 2007. The climate is typically Mediterranean, mean annual rainfall is $970 \mathrm{~mm}$ (dry-warm period in summer and cool-rainy period in autumn), and mean monthly temperatures and rainfall ranges from $7^{\circ} \mathrm{C}$ and $78 \mathrm{~mm}$ in January to $22^{\circ} \mathrm{C}$ and $24 \mathrm{~mm}$ in July, respectively. Soil physical properties were $57.8 \%$ sand; $22.4 \%$ silt; 19.7 clay; $\mathrm{pH} 6.3 ; 1.4 \%$ organic matter.
A randomized experimental design with three replications was adopted; the size of block was $5 \times 5 \mathrm{~m}$. The treatments consisted of oat biomass incorporation into the soil compared to bare soil. On December 6, the field was ploughed, disked and smoothed with a harrow, and A. sativa var. Argentina was drilled at $150 \mathrm{~kg}$ seeds ha ${ }^{-1}$. The control plot (bare soil) was prepared with the same tillage method used for oat crop. Oat production was determined, immediately before their incorporation into the soil, by harvesting $1 \mathrm{~m}^{2}$ area from each block. Fresh biomass was incorporated into the soil on 21 May with a disk harrow at a depth of $10-15 \mathrm{~cm}$ when oat plants were at the stage of anthesis (stage 60 of the scale of Zadoks et al. 1974). The block with bare soil was also plowed. After 6 weeks from soil incorporation, the individual number and biomass (dry weight) of all weed species was determined by harvesting all plants in a $1 \mathrm{~m}^{2}$ area.

Data were tested for homogeneity of variance using Bartlett test (Snedecor and Cochran 1989). One-way ANOVA was performed on $\log _{10}$ transformed data when necessary; retransformed data are presented in the result section.

\section{Extraction and fractionation}

Immediately before the incorporation into the soil, the aerial parts of the plant were harvested, oven dried, and chopped into small pieces. Aerial parts of oat (100 g dry weight) were extracted with a methanol-water $8: 1$ solution by exhaustive maceration $(5 \times 100 \mathrm{~mL})$ to yield $19.8 \mathrm{~g}$ of residue, which was successively partitioned between $n$-hexane and water. The water portion was further partitioned between $n$-butanol and water to obtain 5.2 and $7.0 \mathrm{~g}$ of dried extract, respectively. The dried $n$-butanol extract was further purified by solid phase extraction (SPE) RP-18 eluting with methanol-water 9:1 and, after filtration, analyzed by liquid chromatography coupled with photo diode array and electrospray ionization mass spectrometry (LCPDA-ESI-MS) $(1.0 \mathrm{mg} / \mathrm{mL}$ methanol solution). Part of the $n$-butanol extract $(1.6 \mathrm{~g})$ was successively subjected to SPE (RP-18) with methanol-water 2:1 as the solvent to elute the flavonoid fraction and with methanol-water 7:3 to separate the saponin portion, as indicated by LC-PDA-ESI-MS results.

\section{Bioassay}

The amounts of samples used for the bioassays were calculated on the basis of the dry weight of the extracted material. The extracts (total extract, $n$-butanol, and water fractions) were dissolved in distilled water to yield six different concentrations $(3.3,4.0,5.0,6.7,10.0$, and $20.0 \mathrm{mg} / \mathrm{mL}$ ). The $n$-butanol fraction was then separated 
Table 1 Number and weight of weed species following oat soil incorporation and in bare soil

\begin{tabular}{|c|c|c|c|c|}
\hline Weed species & $\begin{array}{l}\text { Oat } \\
\left(\mathrm{n} \mathrm{m}^{-2}\right)\end{array}$ & $\begin{array}{l}\text { Bare soil } \\
\left(\mathrm{n} \mathrm{m}^{-2}\right)\end{array}$ & $\begin{array}{l}\text { Oat } \\
\text { (dry weight, } \mathrm{g} \mathrm{m}^{-2} \text { ) }\end{array}$ & $\begin{array}{l}\text { Bare soil } \\
\left(\text { dry weight, } \mathrm{g} \mathrm{m}^{-2} \text { ) }\right.\end{array}$ \\
\hline Anagallis spp. & $0(0.0)$ & $4.0(3.0)$ & $0(0.0)$ & $0.2(0.1)$ \\
\hline Chenopodium album & $1.3(1.0)$ & $0(0.0)$ & $16.5(13.1)$ & $0(0.0)$ \\
\hline Fumaria officinalis & $0(0.0)$ & $1.3(1.2)$ & $0(0.0)$ & $0.1(0.1)$ \\
\hline Picris echioides & $12.0(6.1)$ & $202.7(17.0)$ & $19.5(6.2)$ & $130.8(13.3)$ \\
\hline Sinapis spp. & $1.3(0.8)$ & $4.0(2.5)$ & $0.8(0.8)$ & $2.3(1.8)$ \\
\hline Solanum nigrum & $4.0(2.1)$ & $6.7(1.3)$ & $5.9(4.7)$ & $0.3(0.0)$ \\
\hline Total & $18.6(8.2)$ & $218.7(17.3)$ & $42.7(16.7)$ & $133.1(10.5)$ \\
\hline
\end{tabular}

Values are means with standard error in parenthesis

Fig. 1 Bioassay results of $n$-butanol extract of A. sativa. Values are given as means \pm standard error. Standard errors are not shown because error bars lie within the symbols

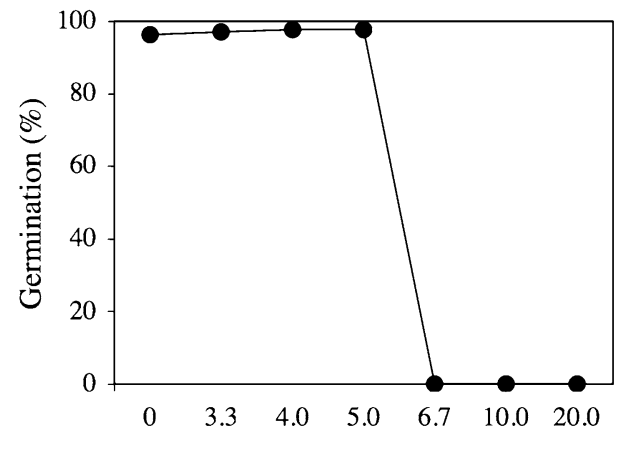

Extract concentration $(\mathrm{mg} / \mathrm{mL})$
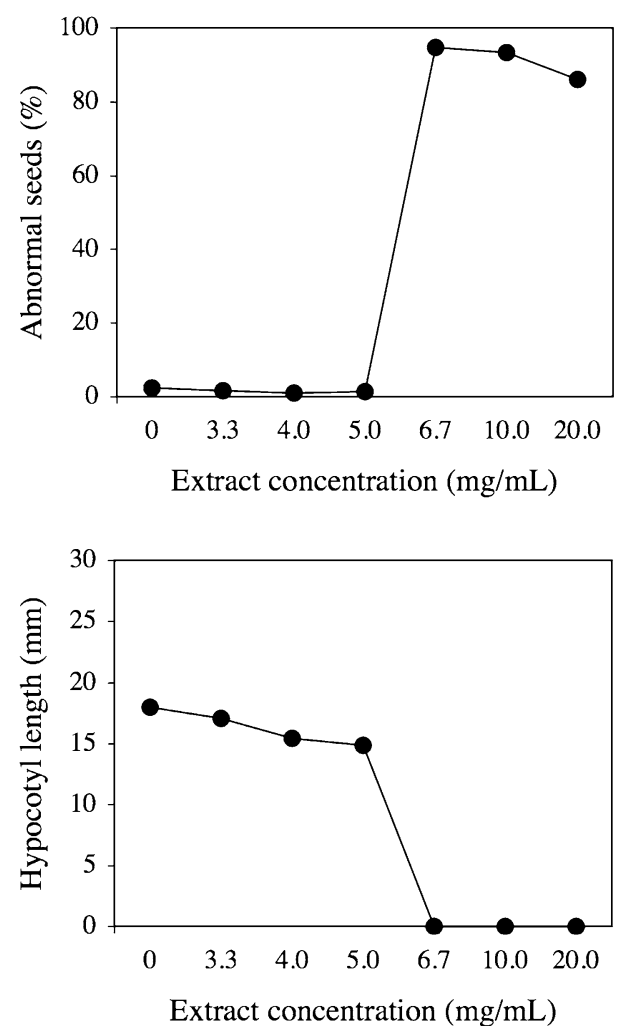
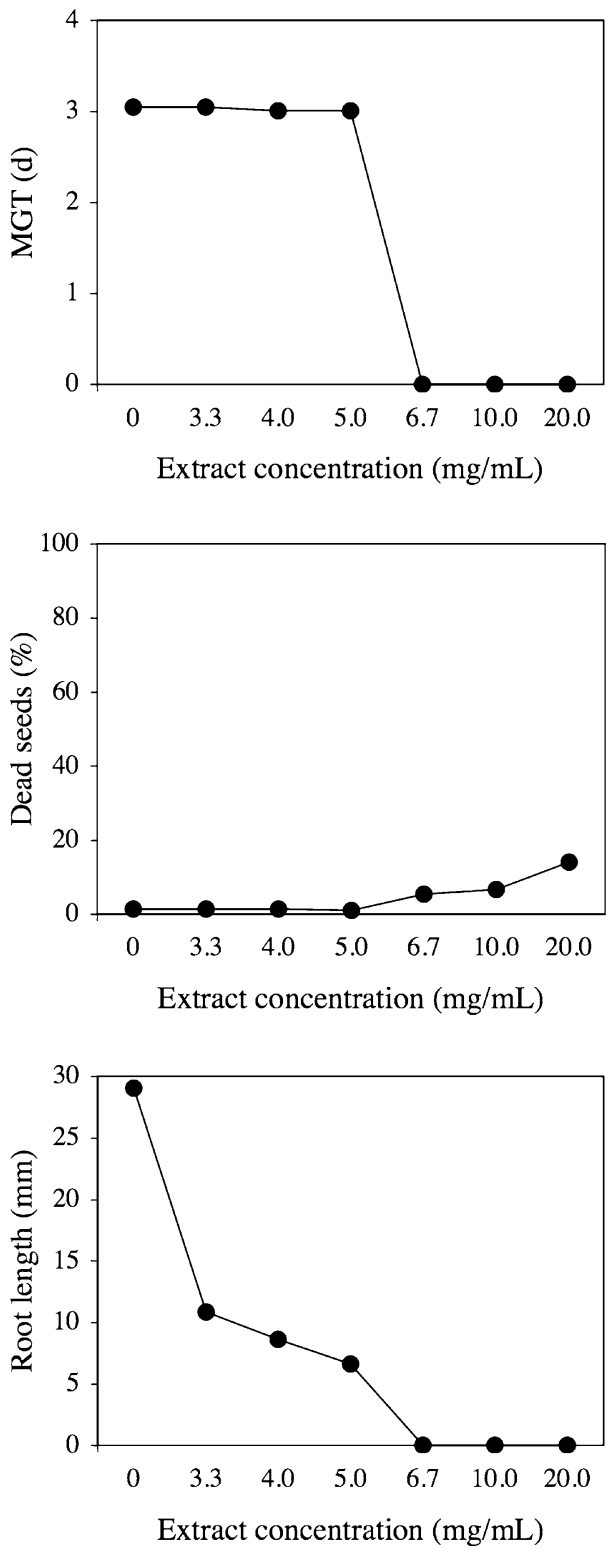

into flavonoid and saponin fractions and tested at 6.7, 10.0, and $20.0 \mathrm{mg} / \mathrm{mL}$, which according to preliminary tests showed the active compounds to be contained in both methanol-water and $n$-butanol fractions. The osmotic potential of each test solution was determined using a cryoscopic osmometer (OSMOMAT 030, Gonotec). The 
osmotic potential of the highest concentrated solution was $114 \mathrm{mOsmol} \mathrm{kg}{ }^{-1}$; the osmotic potential of further dilutions was below $60 \mathrm{mOsmol} \mathrm{kg}{ }^{-1}$. Following Elakovich and Wooten (1991), lettuce seedlings growth is not affected by aqueous extracts with osmotic potential lower than $70 \mathrm{mOsmol} \mathrm{kg}{ }^{-1}$. Thus, the osmotic potential of the extracted solutions at concentrations lower than $20.0 \mathrm{mg} / \mathrm{mL}$ may be considered not to influence germination.

Following Belz and Hurle (2004), the pH of each test solution was also determined to distinguish allelopathy from acidification. Values of extracts ranged from 5.1 to 5.6 in total extract, from 4.0 to 4.3 in $n$-butanol, and from 5.7 to 6.0 in water fractions, respectively. According to Elakovich and Wooten (1991) and Macias et al. (2000), a $\mathrm{pH}$ from 4 to 6 does not affect lettuce germination. Moreover, in a preliminary germination test with distilled water and $\mathrm{pH}$ adjusted to 4.0, the germination of lettuce seeds was not significantly different from the control with distilled water.

The seedling growth assays were done using seeds of lettuce (Lactuca sativa L., Asteraceae, Asterales) with all fractions. Although lettuce is not the species co-occurring with oat, it was selected in this research since it is widely used as a standard target species because of its high sensitivity and fast germination (Macias et al. 2000). Weed species, on the contrary, have longer germination times and low percentage of germination. Under these conditions, the risk of a degradation of the test solution or contamination would be high.

The assays were performed in $20 \mathrm{~cm}$ Petri dishes using 100 seeds and $6 \mathrm{~mL}$ of test solution with three replicates. Dishes were placed in a growth chamber at $20^{\circ} \mathrm{C}$, after $48 \mathrm{~h}$ of prechilling at $4^{\circ} \mathrm{C}$, and were arranged in a randomized complete block design. Dishes were checked regularly, and deionized water was added as needed. For 7 days, germinated seeds were counted at 24-h intervals. A seed was regarded as germinated when the radicle had protruded at least $1 \mathrm{~mm}$. At 7 days after sowing, root and hypocotyl length of germinated seeds was measured on all

Table 2 Effect of flavone $C$-glycoside extract concentrations on lettuce seed germination

\begin{tabular}{lrll}
\hline $\begin{array}{l}\text { Extract } \\
\text { concentration } \\
(\mathrm{mg} / \mathrm{mL})\end{array}$ & $\begin{array}{l}\text { Germinated } \\
\text { seeds }(\%)\end{array}$ & $\begin{array}{l}\text { Abnormal } \\
\text { seedlings }(\%)\end{array}$ & $\begin{array}{l}\text { Dead } \\
\text { seedlings }(\%)\end{array}$ \\
\hline 0 & $96.3(0.7)$ & $2.3(0.9)$ & $1.3(0.3)$ \\
6.7 & $0(0.0)$ & $96.3(0.7)$ & $3.7(0.7)$ \\
10.0 & $0(0.0)$ & $96.7(0.7)$ & $3.3(0.7)$ \\
20.0 & $0(0.0)$ & $93.7(2.0)$ & $6.3(2.0)$ \\
\hline
\end{tabular}

Values are percentage means of three replicates with standard error in parenthesis $(n=100$ seeds per replicate)

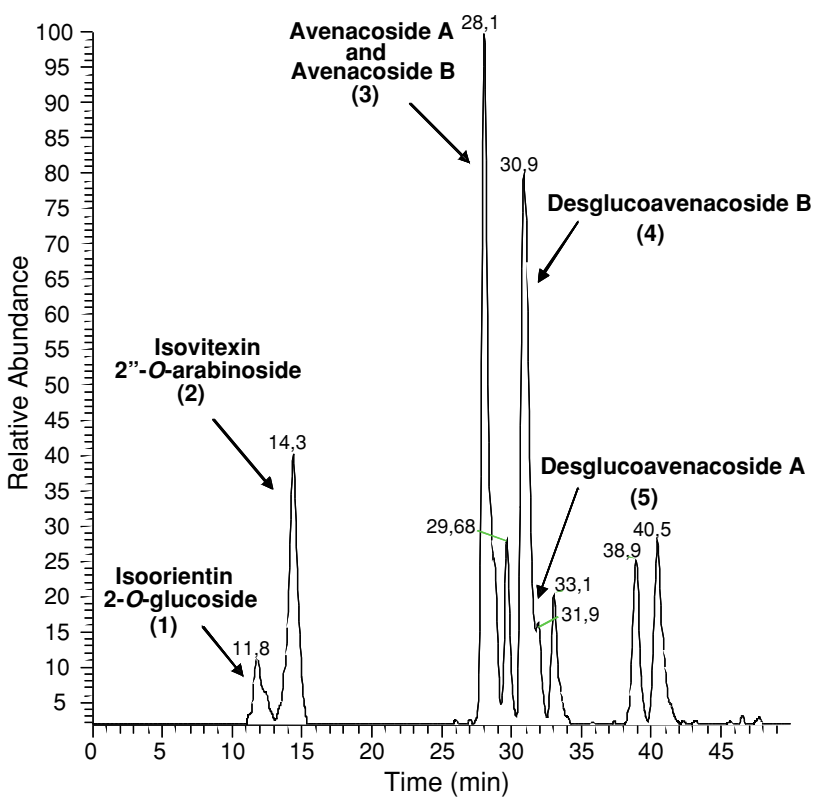

Fig. 2 LC-MS chromatogram of $n$-butanol extract of A. sativa

seedlings in each Petri dish, and the number of abnormal and dead seeds was also recorded, following ISTA (2005).

The mean germination time (MGT) was calculated, following Oyun (2006), as:

$\mathrm{MGT}=\sum(N \times d) / \sum N$

where $N$ is the number of seeds germinated on day $d$, and $d$ is the number of days from the start of the germination test.

Data were tested for homogeneity of variance using Bartlett test (Snedecor and Cochran 1989). One-way ANOVA was performed on $\log _{10}$ transformed data when necessary; back transformed means are presented in the result section. Data were analyzed by Student's $t$ test (Steel and Torrie 1980).

\section{LC-PDA-ESI-MS analyses}

The LC-MS/MS analyses were performed using a Surveyor LC pump, a Surveyor Autosampler, coupled with a LCQ Advantage ion trap mass spectrometer (Thermo Finnigan, San Jose, CA, USA) and equipped with Xcalibur 3.1 software. LC separation was performed on a $4.6 \times$ $150 \mathrm{~mm}$, Sinergi 4 u Fusion RP-80A column (Phenomenex Corp., Torrance, CA, USA). The eluent was a mixture of methanol (solvent A) and water (solvent B). The solvent gradient was as follows: 0-20 min, 30-50\% (A); 20$21 \mathrm{~min}, 50-70 \%$ (A); 21-50 $\mathrm{min}, 70-80 \%$ (A). The elution was performed at a flow rate of $0.8 \mathrm{~mL} / \mathrm{min}$ with a splitting system of 2:8 to MS detector $(200 \mu \mathrm{L})$ and PDA detector $(800 \mu \mathrm{L})$, respectively. The total run time was $50 \mathrm{~min}$. The volume of the injection was $20 \mu \mathrm{L}$. The analysis was performed with an ESI interface in the negative ion mode. The 
ionization conditions were optimized and the following parameters were used: capillary temperature $280^{\circ} \mathrm{C}$, capillary voltage $3 \mathrm{~V}$, tube lens offset $55 \mathrm{~V}$, sheath gas flow rate 60 , auxiliary gas flow rate 6.0 , source voltage $4.5 \mathrm{KV}$. $\mathrm{N}_{2}$ was used as sheath and auxiliary gas. Mass spectra were recorded in a mass range of $m / z, 150-1500$. PDA data were recorded with $220-480 \mathrm{~nm}$.

\section{Results}

\section{Field experiment}

At soil incorporation, dry weight of A. sativa was $489.6 \mathrm{~g} \mathrm{~m}^{-2}$, which is an expected value for oat as cover crop in this environment. Oat showed a species-specific impact on weeds and provided an effective control, as it significantly reduced both the number and the dry weight of all weed species, with the exception of Chenopodium
(Table 1). Among weeds, Picris echioides was the most abundant species, and the number of individuals as well as their dry weight were reduced by 94 and $85 \%$, respectively.

\section{Bioassay}

The plant biomass was initially extracted with methanolwater 8:1 and tested for phytotoxic activity. The extract was active and partitioned between $n$-butanol and water. The $n$-butanol fraction was active, whereas the water fraction was completely inactive. Since methanol-water and $n$-butanol extracts caused similar effects on lettuce seeds on the whole range of concentrations examined, only the results of $n$-butanol extract are reported.

The $n$-butanol extract of A. sativa significantly affected the germination rate of lettuce, as well as the development of seedlings (Fig. 1). The magnitude of the effect was dependent on the concentration. Germination was completely inhibited at extract concentrations higher than $6.7 \mathrm{mg} / \mathrm{mL}$,
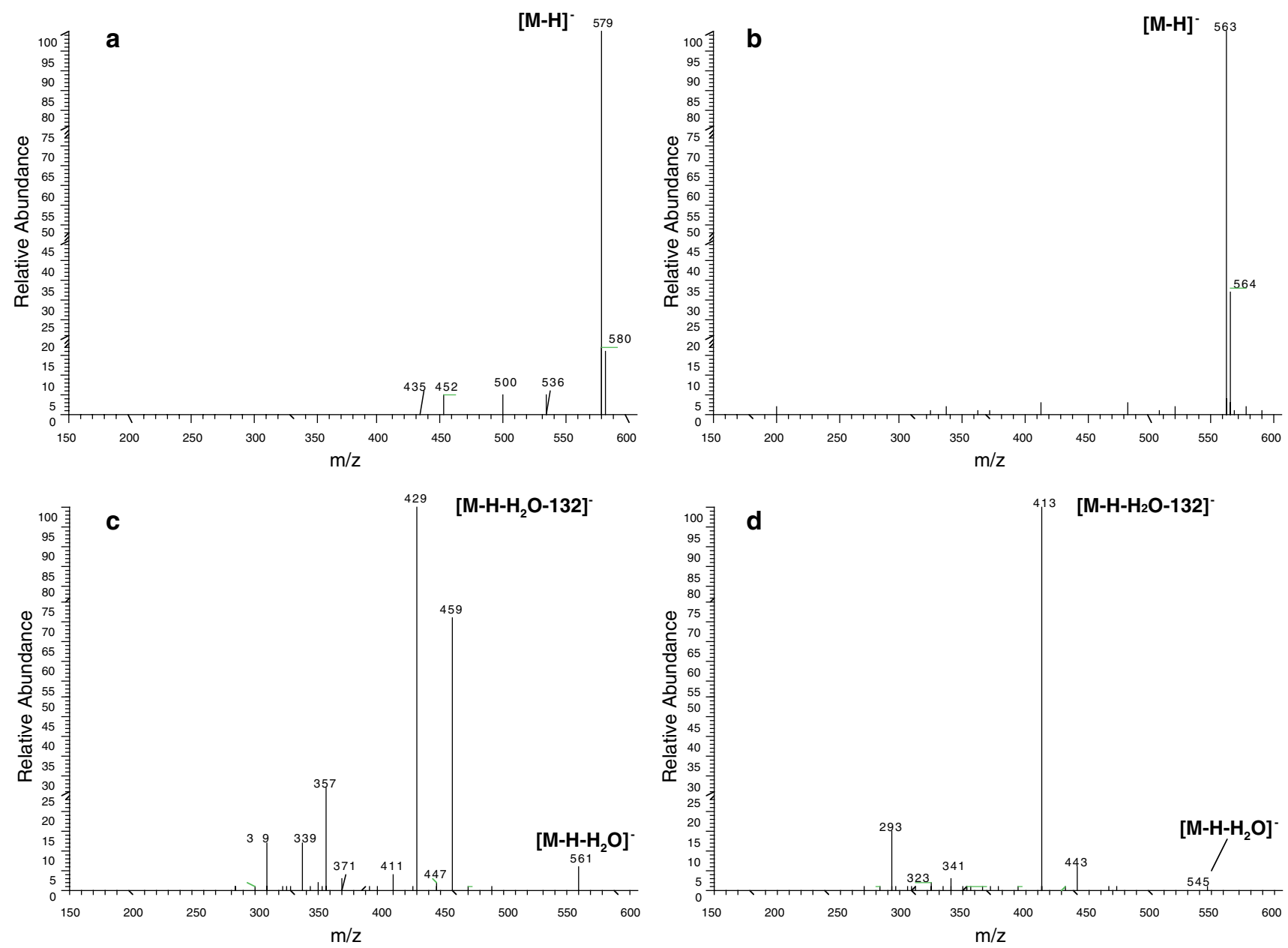

Fig. 3 ESI-MS spectra of $[\mathrm{M}-\mathrm{H}]^{-}$precursor ions of isoorientin 2-O-glucoside (a) and isovitexin $2^{\prime \prime}$-O-arabinoside (b), MS/MS spectra of isoorientin 2-O-glucoside (c) and isovitexin $2^{\prime \prime}$ - $O$-arabinoside (d) 
while it was not affected at lower concentrations of 5.0 $\mathrm{mg} / \mathrm{mL}$ and below. Similarly, the MGT was not modified, compared to the control, by concentrations from 3.3 to $5.0 \mathrm{mg} / \mathrm{mL}$. The reduction of germination percentage depended mainly on the increase of the number of abnormal seedlings, as the number of ungerminated seeds was not greatly affected. The $n$-butanol extract showed inhibitory activity on hypocotyl and root elongation at lower concentrations. An extract concentration of $3.3 \mathrm{mg} / \mathrm{mL}$ resulted in a $63 \%$ reduction in root length while the hypocotyl length was reduced by $5 \%$ when compared with controls.

The $n$-butanol fraction was successively separated into flavonoid and saponin fractions. Solutions of 6.7, 10.0, and $20.0 \mathrm{mg} / \mathrm{mL}$, which were the active dilutions in both methanol-water and $n$-butanol residues, were tested. Phytotoxic activity was detected in the flavonoid fraction, whereas the saponin fraction did not demonstrate any activity. Germination was completely inhibited at all flavonoid concentrations tested, and the number of abnormal seeds was greatly increased from $2 \%$ of control to over $90 \%$ in seeds treated with extract. The number of dead seeds increased with increasing concentration of extract applied with over fourfold increase between control and the highest concentration tested (Table 2).

\section{Identification of allelochemical agents}

The $n$-butanol extract of $A$. sativa, which showed a significant phytotoxic activity, was subjected to HPLC using PDA and ESI-MS as detectors. The resulting chromatogram is shown in Fig. 2. The peaks $\mathbf{1}$ and $\mathbf{2}$ were identified as flavone $C$-glycosides whereas peaks 3-5 were identified as saponins. Both classes of compounds have previously been reported as metabolites isolated from $A$. sativa (Bahraminejad et al. 2008). The identification of compounds was performed on the basis of their UV spectra, molecular weight, and pattern fragmentation of precursor ions deduced by ESI-MS/MS spectra. UV spectra of peaks 1 and $\mathbf{2}$ were typical of flavonoids with absorbance at 270 and $340 \mathrm{~nm}$. Full mass spectra of peaks 1 and 2 showed deprotonated molecules $[\mathrm{M}-\mathrm{H}]^{-}$at $m / z 579$ and 563, respectively (Fig. 3a, b). The MS/MS spectra of precursor ions $m / z 579$ and 563 displayed diagnostic product ions at $\mathrm{m} / \mathrm{z} 561$ and 545, respectively, generated by the loss of a water molecule, and at $m / z 429$ and 413 , generated by the subsequent loss of a glucose and an arabinose unit, respectively (Fig. 3c, d). Comparison with data reported in the literature about flavonoids isolated in oat suggested the assignment of peak $\mathbf{1}$ as isoorientin 2-O-glucoside (Chopin et al. 1977) and peak 2 as isovitexin $2^{\prime \prime}-O$-arabinoside (Saleh et al. 1988). The structures are shown in Fig. 4. Peaks 3 and 4 showed a signal for the ion $\left[\mathrm{M}+\mathrm{HCOO}^{-}\right.$at $\mathrm{m} / z 1107$ corresponding to $M=1062 \mathrm{amu}$. On the basis of

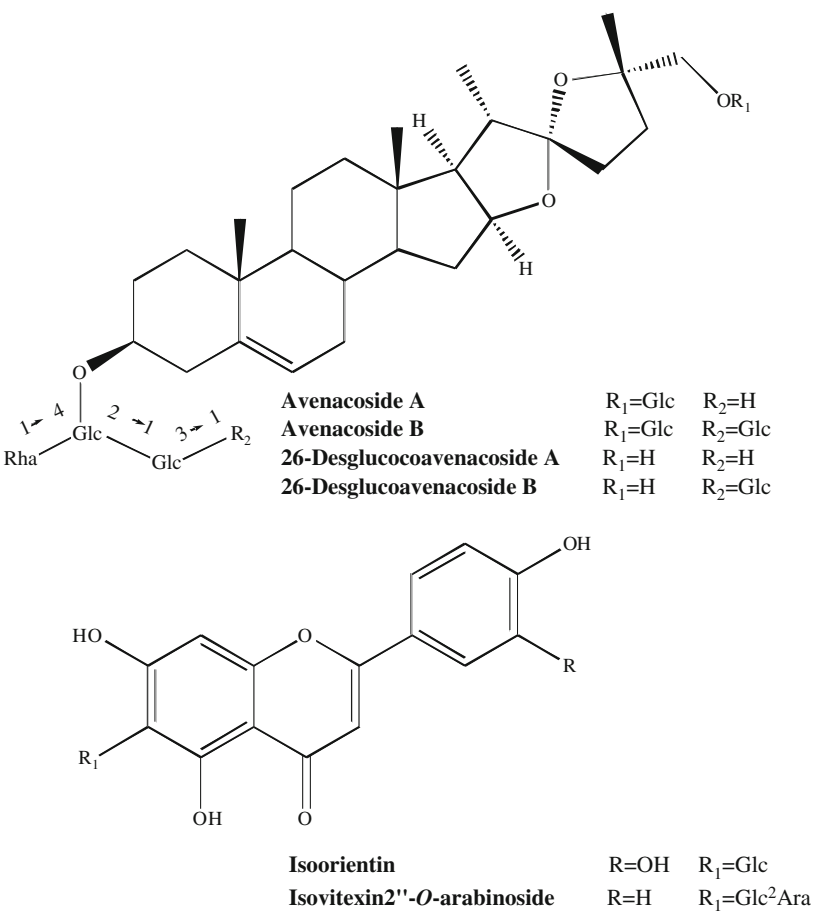

Fig. 4 Structures of saponins and flavonoids from A. sativa

these data and the elution order reported in the literature (Bahraminejad et al. 2008), peaks 3 and $\mathbf{4}$ were identified as the saponins avenacoside $\mathrm{A}\left(t_{R}=28.1 \mathrm{~min}\right)$ and 26-desglucoavenacoside $\mathrm{B}\left(t_{R}=30.9 \mathrm{~min}\right)$, respectively. The full mass spectrum registered for peak 5 characterized an ion $\left[\mathrm{M}+\mathrm{HCOO}^{-}\right.$at $\mathrm{m} / z, 945$ suggesting this compound to be 26-desglucoavenacoside $\mathrm{A}\left(t_{R}=31.9 \mathrm{~min}\right)$. Another saponin, reported to be isolated from $A$. sativa, is avenacoside B with $M=1224$ amu. An extraction ion chromatogram of $\left[\mathrm{M}+\mathrm{HCOO}^{-}\right] \quad m / z \quad 1269$ (Fig. 5c) revealed the presence of this compound in the $n$-butanol extract at $t_{R}=28.1 \mathrm{~min}$, co-eluting with avenacoside A $\left(t_{R}=28.1 \mathrm{~min}\right)$. A compound eluting at $t_{R}=29.7 \mathrm{~min}$ showed an ion $\left[\mathrm{M}+\mathrm{HCOO}^{-}\right.$at $\mathrm{m} / \mathrm{z} 783$ corresponding to the loss of an hexose unit from 26-desglucoavenacoside A at $\mathrm{m} / \mathrm{z}$ 945. Isolation of this compound is not reported in the literature, which suggests that a novel saponin may be detected in A. sativa. Peaks at $t_{R}=38.9$ and $40.5 \mathrm{~min}$, corresponding to protonated molecules at $\mathrm{m} / \mathrm{z}, 714$ and 721 , respectively, seemed not to be correlated to (known) oat saponin structures. The fragmentation pattern of their precursor ion did not suggest any correlation with secondary metabolites described from oat. They remain unidentified.

\section{Discussion}

Results of the field experiment demonstrated that soil incorporation of $A$. sativa provided a satisfactory control 
Fig. 5 Extracted ion chromatogram for $m / z, 1107$ (b) and $1269(\mathbf{c})$. The total chromatogram is shown in $\mathbf{a}$
(3)
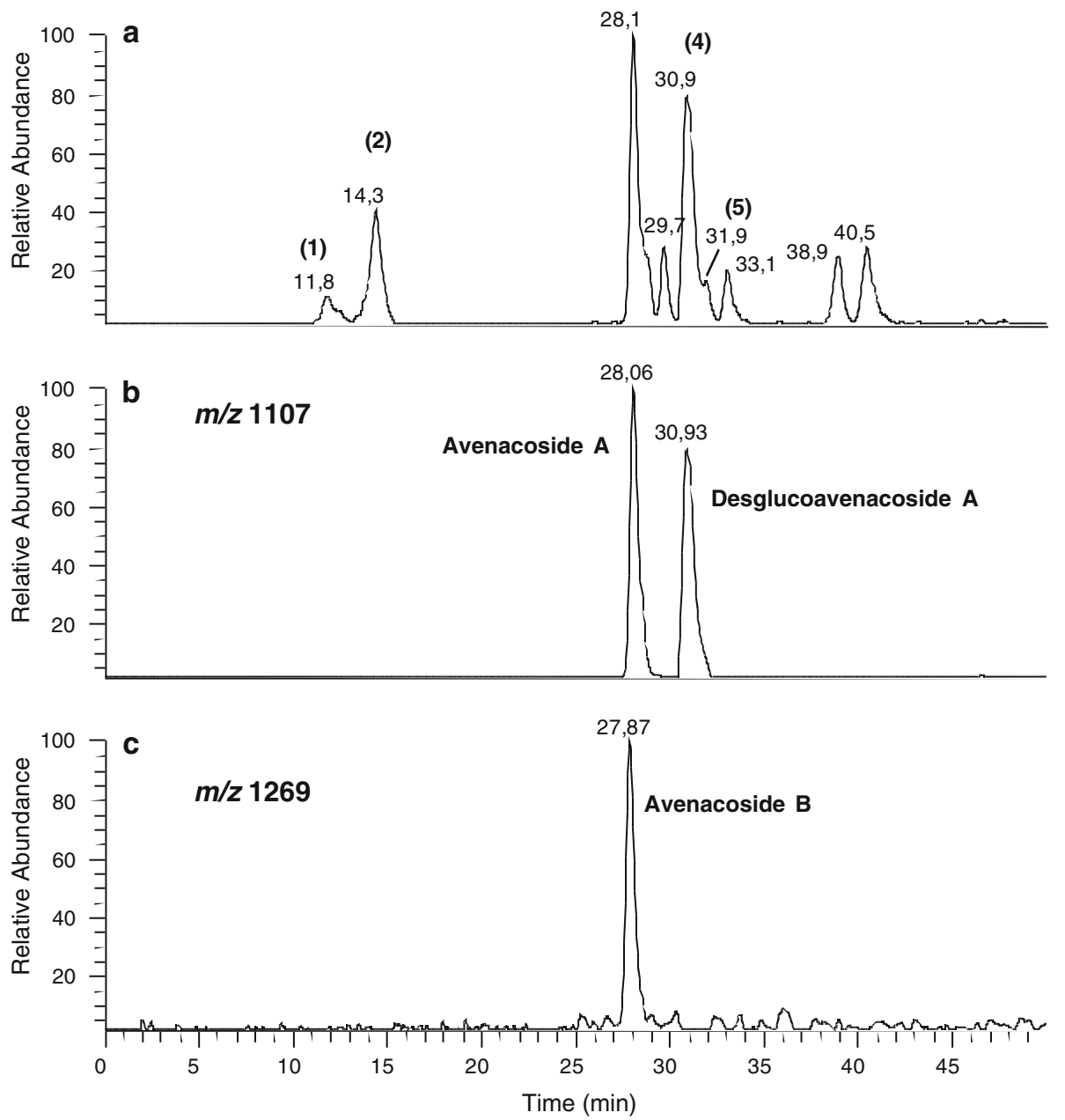

of weeds, inhibiting the germination of seeds and reducing the growth of the germinated seedlings. This effect is probably due to the release of allelochemicals during the decomposition of biomass following incorporation in the soil. We concede that phytotoxicity of flavonoids was demonstrated in bioassays and thus we cannot directly attribute the suppression of weeds observed in the field to these compounds. Further research should be carried out to demonstrate their activity in the field. The response of weeds to oat incorporation into soil is species-specific, and consequently we suggest that repeated soil incorporation is likely to lead to shifts in weed species composition.

In bioassays, the methanol-water, $n$-butanol, and flavonoid extracts of $A$. sativa were toxic to the target species, suggesting the presence of phytotoxins in the plant biomass. The toxic effects on germination were concentrationdependent, as the germination of seeds was not affected by oat extracts at concentrations lower than $6.7 \mathrm{mg} / \mathrm{mL}$, while it was completely inhibited by higher concentrations. Thus, among the tested doses, $6.7 \mathrm{mg} / \mathrm{mL}$ was effective to inhibit lettuce germination. At lower concentrations, however, allelochemicals did not affect the germination rate and time but exerted a toxic effect on seedlings, significantly reducing root extension. This confirmed that root growth is a more sensitive indicator of phytotoxicity than hypocotyl length (Kato-Noguchi et al. 1994).

Analysis of the flavonoid fraction by ESI-MS led to the identification of the flavone $\mathrm{C}$-glycosides isoorientin 2-Oglucoside and isovitexin $2^{\prime \prime}-O$-arabinoside which have been previously described from oat (Chopin et al. 1977; Saleh et al. 1988).

In conclusion, our results provide strong evidence of the allelopathic potential of oat biomass due to flavonoid compounds in accord with recent literature data reporting allelopathic activity for phenolic compounds in oats (Baghestani et al. 1999; Chon and Kim 2004; Hura et al. 2006). 


\section{References}

Baghestani A, Lemieux C, Leroux GD (1999) Determination of allelochemicals in spring cereal cultivars of different competitiveness. Weed Sci 47:498-504

Bahraminejad S, Asenstorfer RE, Riley IT, Schultz CJ (2008) Analysis of the antimicrobial activity of flavonoids and saponins isolated from the shoots of oats (Avena sativa L.). J Phytopathol 156:1-7

Belz R, Hurle K (2004) A novel laboratory screening bioassay for crop seedling allelopathy. J Chem Ecol 30:175-198

Bousquet-Mélou A, Louis S, Robles C, Greff S, Dupouyet S, Fernandez C (2005) Allelopathic potential of Medicago arborea, a Mediterranean invasive shrub. Chemoecology 15:193-198

Chon SU, Kim YM (2004) Herbicidal potential and quantification of suspected allelochemicals from four grass crop extracts. J Agron Crop Sci 190:145-150

Chopin J, Dellamonica G, Bouillant ML, Besset A, Popovici G, Weissenboeck G (1977) C-glycosilflavones from Avena sativa. Phytochemistry 16:2041-2043

Duke SO, Dayan FE, Romagni JG, Rimando AM (2000a) Natural products as sources of herbicides: current status and future trends. Weed Res 40:99-111

Duke SO, Dayan FE, Romagni J (2000b) Natural products as sources for new mechanisms of herbicidal action. Crop Prot 19:583-589

Duke SO, Dayan FE, Rimando AM, Shrader K, Aliotta G, Oliva A, Romagni JG (2002) Chemicals from nature for weed management. Weed Sci 50:138-151

Elakovich SD, Wooten JW (1991) Allelopathic potential of Nuphar lutea (L.) Sibth. \& SM. (Nymphaeaceae). J Chem Ecol 17:707715

Fay PK, Duke WB (1977) An assessment of allelopathic potential in Avena germ plasm. Weed Sci 25:224-228

Hura T, Dubert F, Dabkowska T, Stupnicka-Rodzynkiewicz E, Stoklosa A, Lepiarczyk A (2006) Quantitative analysis of phenolics in selected crop species and biological activity of these compounds evaluated by sensitivity of Echinochloa crusgalli. Acta Physiol Plant 28:537-545

Inderjit WLA (2001) Soil: environmental effects on allelochemical activity. Agron J 93:79-84
Inderjit WLA (2005) Soil microorganisms: an important determinant of allelopathic activity. Plant Soil 274:227-236

Inderjit WLA, Duke SO (2005) Challenges, achievements and opportunities in allelopathy research. J Plant Interact 1:69-81

ISTA (2005) International rules for seed testing. The International Seed Testing Association, Basserdorf, pp 5-19

Kato-Noguchi H, Kosemura S, Yamamura S, Mizutani J, Hasegawa K (1994) Allelopathy of oats: assessment of allelopathic potential of extract of oat shoots and identification of an allelochemical. J Chem Ecol 20:309-314

Macias FA, Castellano D, Molinillo JMG (2000) Search for a standard phytotoxic bioassay for allelochemicals. Selection of standard target species. J Agric Food Chem 48:2512-2521

Oyun MB (2006) Allelopathic potentialities of Gliricidia sepium and Acacia auriculiformis on the germination and seedling vigour of maize (Zea mays L.). Am J Agric Biol Sci 1:44-47

Putnam AR (1986) Can it be managed to benefit horticulture? Hort Sci 21:411-413

Rice EL (1984) Allelopathy. Academic Press Inc., Orlando

Rimando AM, Olofsdotter M, Dayan FE, Duke S (2001) Searching for rice allelochemicals: an example of bioassay-guided isolation. Agron J 93:16-20

Saleh NAM, Nozzolillo C, Altosaar I (1988) Flavonoids variation in Avena species. Biochem Syst Ecol 16:597-599

Snedecor GW, Cochran WG (1989) Statistical methods, 8th edn. Iowa State University Press, IA

Soriano IR, Asenstorfer RE, Schmidt O, Riley IT (2004) Inducible flavone in oats (Avena sativa) is a novel defense against plantparasitic nematodes. Nematology 94:1207-1214

Steel RGD, Torrie JH (1980) Principles and procedures of statistics: a biometrical approach. McGraw-Hill, New York

Weston LA (1996) Utilization of allelopathy for weed management in agroecosystems. Agron J 88:860-866

Weston LA, Duke SO (2003) Weed and crop allelopathy. Crit Rev Plant Sci 22:367-389

Zadoks JC, Chang TT, Konzak CF (1974) A decimal code for the growth stages of cereals. Weed Res 14:415-421 